\title{
The Association of Vitamin D Deficiency and Insufficiency with Diabetic Nephropathy: Implications for Health Disparities
}

\author{
Vanessa A. Diaz, MD, MS, Arch G. Mainous III, PhD, Peter J. Carek, MD, MS, \\ Andrea M. Wessell, PharmD, and Charles J. Everett, PhD
}

Objective: To evaluate the association between vitamin D deficiency and insufficiency with diabetic nephropathy across racial/ethnic groups.

Methods: Cross-sectional analysis of the 2001 to 2006 National Health and Nutrition Examination Survey. A nationally representative sample of 1216 adults ( $\geq 20$ years old) with diagnosed diabetes provides population estimates for $>\mathbf{1 2 . 6}$ million individuals. Nephropathy was defined as urinary albuminto-creatinine ratio $\geq 30 \mathrm{mg} / \mathrm{g}$ in a random spot urine sample. Serum 25 -hydroxycalciferol vitamin D levels were characterized as $<20 \mathrm{ng} / \mathrm{mL}$ vitamin D deficiency, 20 to $29 \mathrm{ng} / \mathrm{mL}$ vitamin D insufficiency, and $\geq 30 \mathrm{ng} / \mathrm{mL}$ normal vitamin $D$.

Results: Overall, $30.7 \%$ of adults with diabetes have nephropathy, $48.9 \%$ have vitamin $D$ deficiency and 36.6\% have vitamin D insufficiency. Minorities are more likely to have nephropathy (non-Hispanic whites, 27.8\%; non-Hispanic blacks, 36.2\%; Hispanics 38.5\%; $P=.02$ ) and vitamin D deficiency (nonHispanic whites, 39.5\%; non-Hispanic blacks, 80.4\%; Hispanic, 59.0\%; $P<.01$ ). Higher proportions of individuals with nephropathy have vitamin $D$ deficiency than individuals without nephropathy $(53.2 \%$ vs $47.0 \% ; P=.03)$. Logistic regressions demonstrate vitamin $D$ deficiency and insufficiency are associated with the presence of nephropathy after adjustment for race/ethnicity, age, sex, hypertension, high cholesterol, smoking status, and use of angiotensin-converting enzyme inhibitors or angiotensin receptor blockers (odds ratio, 1.85; 95\% CI, 1.06-3.23 for vitamin D deficiency; and odds ratio, 1.79; 95\% CI, 1.12-2.85 for vitamin D insufficiency).

Conclusions: There is a high prevalence of vitamin D deficiency and insufficiency in individuals with diabetes; minorities have the highest prevalences. Thus, evaluating vitamin D levels in people with diabetes may be warranted. There is an independent association between vitamin D deficiency and vitamin D insufficiency with the presence of nephropathy, even after adjustment for race/ethnicity and other variables. Further studies of this relationship may lead to new interventions that decrease health disparities in the progression of diabetic nephropathy. (J Am Board Fam Med 2009;22:521-527.)

\section{Background}

Diabetic nephropathy is a risk factor for cardiovascular disease and the leading cause of chronic kidney disease in patients starting renal replacement therapy. ${ }^{1}$ Racial and ethnic differences exist in the prevalence of diabetic nephropathy. A study evaluating people with diabetes in the United States

\footnotetext{
This article was externally peer reviewed.

Submitted 6 November 2008; revised 9 February 2009; accepted 12 February 2009.

From the Department of Family Medicine, Medical University of South Carolina, Charleston.

Funding: Supported in part by a grant from the Robert Wood Johnson Foundation.

Conflict of interest: none declared.

Corresponding author: Vanessa A. Diaz, MD, Medical University of South Carolina, Department of Family Medicine, 295 Calhoun Street, MSC 192, Charleston, SC 29425 (E-mail: diazva@musc.edu).
}

shows that non-Hispanic blacks and Hispanics are less likely to have normal renal function than nonHispanic whites. ${ }^{2}$ Similarly, the incidence of reported end-stage renal disease in people with diabetes is more than 4 times as high in African Americans and 4 to 6 times as high in Mexican Americans than in the general population of diabetes patients. ${ }^{3}$ These disparities exist despite similar proportions of blacks, whites, and Hispanics meeting recommendations for glycolated hemoglobin and blood pressure control and similar proportions with rennin-angiotensin system blockade via use of angiotensin-converting enzyme (ACE) inhibitors or angiotensin II type 1 receptor blockers (ARBs). ${ }^{2}$ Thus, reasons for the racial/ethnic disparities seen in diabetic nephropathy are unclear.

A factor that may impact the differential development of diabetic nephropathy is vitamin D. The 
role of the kidney in the hydroxylation of the vitamin D metabolite 25-hydroxycalciferol (25-OH-D) from the liver to the biologically active form of $1,25(\mathrm{OH}) 2 \mathrm{D} 3$ is well established. ${ }^{4,5}$ Animal studies suggest that, in addition to the impact that chronic renal failure has on increasing the likelihood of $1,25(\mathrm{OH}) 2 \mathrm{D} 3$ deficiency and insufficiency caused by the kidney's role in vitamin D metabolism, vitamin D deficiency and insufficiency also have an active role in the progression of kidney disease. ${ }^{6-9}$ Inhibition of the renin-angiotensin system by the vitamin $\mathrm{D}$ metabolite has been demonstrated in vitro; animal studies suggest that receptor-mediated vitamin $\mathrm{D}$ actions have a renoprotective role in diabetic nephropathy. ${ }^{6,7}$ These findings are supported by rat studies that show $1,25(\mathrm{OH}) 2 \mathrm{D} 3 \mathrm{ad}-$ ministration attenuates the development of glomerulosclerosis and the progression of proteinuria through parathyroid hormone-independent antiproliferative actions and decreases in podocyte loss and podocyte hypertrophy. 8 ,9 These findings may be especially pertinent in individuals with diabetic nephropathy because, in addition to the direct impact on renal function, adequate levels of vitamin D are also associated with decreased insulin resistance and reduced blood pressure, the 2 main, potentially modifiable risk factors for diabetic nephropathy initiation and progression. ${ }^{1,10}$ However, little information is available about the association between diabetic nephropathy and vitamin D levels in humans.

It has been estimated that 1 billion people worldwide have vitamin D deficiency or insufficiency. ${ }^{10}$ Minorities are more likely to be deficient in vitamin $\mathrm{D}$ because of low dietary intake as well as the role of solar ultraviolet $\mathrm{B}$ radiation in vitamin $\mathrm{D}$ metabolism, causing the increased pigmentation in groups with darker skin to reduce vitamin $\mathrm{D}$ production in the skin. ${ }^{11,12}$ Thus, the health disparities currently seen in diabetic nephropathy may be partially explained by differences in vitamin $\mathrm{D}$ levels by race/ethnicity. Therefore, this study will evaluate the association between Vitamin D and diabetic nephropathy in a nationally representative sample of people with diabetes.

\section{Methods}

\section{Survey Description}

Data from the 2001 to 2006 National Health and Nutrition Examination Survey (NHANES) was an- alyzed. The NHANES is a product of the National Center for Health Statistics. It is a continuous, annual survey involving participants from a nationally representative sample of noninstitutionalized residents of the United States. Samples are weighted so they are representative of the US population. Sampling weights are calculated by taking into account unequal probabilities of selection caused by sample design, nonresponse and planned over-sampling of minorities, and then matched to population control totals known to be representative of the US population. This allows for the calculation of population estimates for the United States. ${ }^{13}$ The NHANES includes a detailed household interview and physical examination plus laboratory information obtained through mobile examination centers. Data are collected throughout the year across designated data collection communities in the United States. To protect the anonymity of the respondents, the month of data collection and the specific community of origin of the respondent is not released to the public. The reported investigations have been conducted in accordance with the principles of the Declaration of Helsinki as revised in 2000.

\section{Sample}

Adults ( $\geq 20$ years of age) who reported a diagnosis of diabetes by answering yes to the question, "Other than during pregnancy, have you ever been told by a doctor or health professional that you have diabetes or sugar diabetes?" were included in this sample. Participants self-identified as non-Hispanic white, non-Hispanic black, or Hispanic. Because of the small size and heterogeneity of the "Other" racial category, this group was not analyzed.

\section{Definition of Diabetic Nephropathy}

Consistent with American Diabetes Association guidelines, albumin and creatinine were measured in a random spot urine sample. ${ }^{14}$ These measurements were used to calculate the urinary albuminto-creatinine ratio. Values of $<30 \mathrm{mg} / \mathrm{g}$ were characterized as being normal, whereas values $\geq 30$ $\mathrm{mg} / \mathrm{g}$ describe either microalbuminuria or macroalbuminuria. ${ }^{14}$ Thus, in this study, nephropathy was defined as a urinary albumin-to-creatinine ratio $\geq 30 \mathrm{mg} / \mathrm{g}$. 


\section{Definition of Vitamin D Deficiency and Vitamin D Insufficiency}

Vitamin D status in the serum is evaluated based on the Diasorin 25-OH-D assay, which measures 25$\mathrm{OH}-\mathrm{D}$. This is the predominant circulating form of vitamin $\mathrm{D}$ in the normal population and is the most commonly used to determine vitamin D status. ${ }^{4,5}$ Although there is no consensus on optimal levels of $25-\mathrm{OH}-\mathrm{D}$, data suggests that levels $\geq 30 \mathrm{ng} / \mathrm{mL}$ can be considered an indication of sufficient vitamin D. ${ }^{4}$ Thus, individuals with 25-OH-D levels $<20 \mathrm{ng} / \mathrm{mL}$ and 20 to $29 \mathrm{ng} / \mathrm{mL}$ were characterized having vitamin $\mathrm{D}$ deficiency and vitamin $\mathrm{D}$ insufficiency, respectively. This is consistent with recommendations from the National Kidney Foundation. ${ }^{5}$

\section{Medication Use}

Participants were asked to present the containers for all the prescription medications taken during the past month and to report any medications taken for which the container was not available. These medications were then matched by trained survey interviewers to an annually updated comprehensive database of all prescription drugs in the US market. Products not matched to the drug database were edited after data collection at the National Center for Health Statistics, where quality control activities resulted in $<1 \%$ of medications being listed as unknown. All reported medication names were converted to their standard generic ingredient name for data release. ${ }^{15,16}$ These generic names were used to identify medications as ACE inhibitors or ARBs. Use of these medications was included in addition to the diagnosis of hypertension because data suggests that they provide benefits beyond their effect on blood pressure in the prevention and delay of diabetic kidney disease. ${ }^{17,18}$

\section{Definitions of Disease}

Hypertension was assessed by self-report. Individuals who reported ever being told they had hypertension or high blood pressure were classified as having hypertension. Having diagnosed high cholesterol was defined based on the question, "Have you ever been told by a doctor or other health professional that your blood cholesterol level was high?" Individuals answering "No" or "I don't know" or who stated they had not had their cholesterol checked were characterized as not having a diagnosis of high cholesterol. Hypertension and high cholesterol were assessed as possible confounding variables because dyslipidemia and hypertension are established risk factors for diabetic nephropathy. ${ }^{1}$ Obesity was based on body mass index (BMI), calculated using measured weight and height $\left(\mathrm{kg} / \mathrm{m}^{2}\right)$. BMI categories were consistent with 1998 National Heart, Lung and Blood Institute guidelines, which classify obesity as a BMI of $\geq 30.0$.

\section{Smoking Status}

Smoking has been demonstrated to be a putative risk factor for diabetic nephropathy. ${ }^{19,20}$ Smoking status was assessed using 2 questions to characterize individuals as never, former, or current smokers. Current cigarette smoking was defined as answering "Yes" to the question, "Have you smoked at least 100 cigarettes in your entire life?" and answering "Everday" or "Some days" to the question, "Do you now smoke cigarettes?" Individuals who answered "Yes" to the first question and answered "Not at all" to the second question were defined as being a former smoker. Those answering "No" to both questions were defined as never smoking.

\section{Analysis}

Because the NHANES 2001 to 2006 is a complex, stratified cluster sample, standard statistical techniques could not be used. Therefore, we used SUDAAN (Research Triangle Institute, Research Triangle, NC), a specialized statistical program that accounts for the complex weighting of the NHANES sample. Using SUDAAN allowed us to correct for unequal probabilities of selection and different response rates, ensuring that the results could be generalized to the noninstitutionalized civilian population of the United States. Thus the percentages and odds ratios in this study represented weighted values. SUDAAN also adjusts the standard errors to account for the weighting, stratification, and clustering of the complex sampling design to ensure that expressed $P$ is valid. The prevalences of demographic and disease characteristics were assessed within the overall population and also by race/ethnicity, where they were compared using $\chi^{2}$ tests. Similarly, the prevalences of these characteristics were also assessed and compared in those with and without nephropathy. Logistic regressions were used to determine the independent relationship between vitamin $\mathrm{D}$ status and 
Table 1. Demographics and Characteristics of Adults ( $\geq 20$ Years 0ld) with Diagnosed Diabetes

\begin{tabular}{|c|c|c|c|c|c|}
\hline & Total & Non-Hispanic White & Non-Hispanic Black & Hispanic & $P^{*}$ \\
\hline Weighted sample size ( $\mathrm{n}$, in millions) & 12.6 & 8.8 & 2.0 & 1.8 & \\
\hline \multicolumn{6}{|l|}{ Age (\%) } \\
\hline 20 to 45 & 18.4 & 15.0 & 23.8 & 28.4 & \multirow[t]{2}{*}{$<.01$} \\
\hline$>45$ & 81.6 & 85.0 & 76.2 & 71.6 & \\
\hline \multicolumn{6}{|l|}{ Sex $(\%)$} \\
\hline Male & 47.9 & 49.0 & 42.6 & 48.4 & \multirow[t]{2}{*}{.18} \\
\hline Female & 52.1 & 51.0 & 57.4 & 51.6 & \\
\hline \multicolumn{6}{|l|}{ Smoking status (\%) } \\
\hline Never & 47.4 & 47.3 & 44.9 & 50.2 & \multirow[t]{3}{*}{$<.01$} \\
\hline Former & 33.4 & 35.9 & 28.0 & 27.3 & \\
\hline Current & 19.2 & 16.7 & 27.0 & 22.5 & \\
\hline \multicolumn{6}{|l|}{ BMI $\left[\mathrm{kg} / \mathrm{m}^{2}\right](\%)$} \\
\hline$<30$ & 43.3 & 41.6 & 38.3 & 57.0 & \multirow[t]{2}{*}{.01} \\
\hline$\geq 30$ & 56.7 & 58.4 & 61.7 & 43.0 & \\
\hline Nephropathy (\%) & 30.7 & 27.8 & 36.2 & 38.5 & .02 \\
\hline Diagnosed hypertension (\%) & 64.2 & 65.5 & 74.9 & 46.0 & $<.01$ \\
\hline Diagnosed high cholesterol (\%) & 57.6 & 60.8 & 50.2 & 50.7 & .02 \\
\hline On ACE inhibitors/ARB (\%) & 11.9 & 12.8 & 11.1 & 8.6 & .37 \\
\hline \multicolumn{6}{|l|}{ Vitamin D (\%) } \\
\hline$<20 \mathrm{ng} / \mathrm{mL}$ & 48.9 & 39.5 & 80.4 & 59.0 & \multirow[t]{3}{*}{$<.01$} \\
\hline 20 to $29 \mathrm{ng} / \mathrm{mL}$ & 36.6 & 41.2 & 18.1 & 34.8 & \\
\hline$\geq 30 \mathrm{ng} / \mathrm{mL}$ & 14.5 & 19.2 & 1.5 & 6.1 & \\
\hline
\end{tabular}

*P calculated using $\chi^{2}$ tests.

BMI, Body Mass Index; ACE, angiotensin-converting enzyme; ARB, angiotensin II type 1 receptor blockers.

diabetic nephropathy. An unadjusted regression was computed initially. Regressions adjusting for race/ethnicity, age, sex, and for these demographic variables in addition to other predictor variables were also computed. The other predictor variables evaluated were hypertension, high cholesterol, smoking status, obesity, and use of an ACE inhibitor or ARB. $P<.05$ was determined to be significant.

\section{Results}

The inclusion criteria for this study provided an unweighted sample size of 1216 , which could be used to provide population estimates for more than 12.6 million individuals. Overall, $48.9 \%$ of the participants had vitamin D deficiency $(<20 \mathrm{ng} / \mathrm{mL})$ and $36.6 \%$ of the participants had vitamin D insufficiency. The mean vitamin $\mathrm{D}$ concentration in our sample was $20.6 \mathrm{ng} / \mathrm{mL}$ (95\% CI, 19.6-21.6). Demographic and disease characteristics for adults with diabetes by race/ethnicity are presented in Table 1. Differences in age and sex exist by race/ ethnicity, with non-Hispanic whites being older and a higher proportion of non-Hispanic blacks being women. Minorities had a higher proportion of individuals with nephropathy and were more likely to have vitamin D deficiency. In fact, $80 \%$ of non-Hispanic blacks and 59\% of Hispanics with diabetes exhibited vitamin $\mathrm{D}$ deficiency.

As seen in Table 2, higher proportions of individuals with nephropathy had vitamin $\mathrm{D}$ deficiency versus individuals without nephropathy. Table 3 presents results from logistic regressions, which demonstrate that this relationship remains even after controlling for demographic variables such as race/ethnicity, age, and sex as well as other variables. The odds ratios for the unadjusted and adjusted relationships remained similar, demonstrating the independent nature of the relationship between low levels of serum vitamin D and the presence of nephropathy. We also tested the relationship between urinary albumin-to-creatinine ratio and vitamin $\mathrm{D}$ (both continuous) in linear regressions. The unadjusted $\beta$ for vitamin $\mathrm{D}$ was -9.49 (95\% CI, -15.09 to -3.88$)$ and was significant at $P=.01$. Adjusting for demographic vari- 
Table 2. Demographics and Characteristics of Adults ( $\geq 20$ Years 01d) with Diagnosed Diabetes by Nephropathy Status

\begin{tabular}{|c|c|c|c|}
\hline & Nephropathy & No Nephropathy & $P$ \\
\hline \multicolumn{4}{|l|}{ Age (\%) } \\
\hline 20 to 45 & 17.8 & 18.6 & \multirow[t]{2}{*}{.81} \\
\hline$>45$ & 82.2 & 81.4 & \\
\hline \multicolumn{4}{|l|}{ Sex $(\%)$} \\
\hline Male & 56.4 & 44.1 & \multirow[t]{2}{*}{$<.01$} \\
\hline Female & 43.6 & 55.9 & \\
\hline \multicolumn{4}{|l|}{ Race/Ethnicity (\%) } \\
\hline Non-Hispanic white & 62.9 & 72.3 & \multirow[t]{3}{*}{.0} \\
\hline Non-Hispanic black & 18.9 & 14.8 & \\
\hline Hispanic & 18.2 & 12.9 & \\
\hline \multicolumn{4}{|l|}{$\mathrm{BMI}\left[\mathrm{kg} / \mathrm{m}^{2}\right](\%)$} \\
\hline$<30$ & 42.9 & 43.5 & \multirow[t]{2}{*}{.87} \\
\hline$\geq 30$ & 57.1 & 56.5 & \\
\hline Diagnosed hypertension (\%) & 72.3 & 60.6 & $<.01$ \\
\hline Diagnosed high cholesterol (\%) & 52.8 & 59.8 & .08 \\
\hline \multicolumn{4}{|l|}{ Smoking status (\%) } \\
\hline Never & 39.9 & 50.7 & \multirow[t]{3}{*}{.01} \\
\hline Former & 37.4 & 31.7 & \\
\hline Current & 22.7 & 17.7 & \\
\hline On ACE inhibitors/ARB (\%) & 15.3 & 10.4 & .02 \\
\hline \multicolumn{4}{|l|}{ Vitamin D (\%) } \\
\hline$<20 \mathrm{ng} / \mathrm{mL}$ & 53.2 & 47.0 & \multirow[t]{3}{*}{.03} \\
\hline 20 to $29 \mathrm{ng} / \mathrm{mL}$ & 37.2 & 36.4 & \\
\hline$\geq 30 \mathrm{ng} / \mathrm{mL}$ & 9.6 & 16.6 & \\
\hline
\end{tabular}

${ }^{*} P$ calculated using $\chi^{2}$ tests.

BMI, Body Mass Index; ACE, angiotensin-converting enzyme; ARB, angiotensin II type 1 receptor blockers.

ables the $\beta$ for vitamin $\mathrm{D}$ was -8.77 (95\% CI, -13.93 to -3.61$)$, which was significant at $P=.01$. In the fully adjusted regression, vitamin $D$ had a $\beta$ of -8.94 (95\% CI, -14.29 to -3.60$)$, significant at $P=.01$. In a subanalysis excluding persons with macroalbuminuria, vitamin $\mathrm{D}<30 \mathrm{ng} / \mathrm{mL}$ had an odds ratio of 1.78 (95\% CI, 1.02-3.08) for nephropathy when compared with vitamin $\mathrm{D}>30$ $\mathrm{ng} / \mathrm{mL}$, indicating that the relationship holds for persons with less significant disease.

\section{Discussion}

Findings from this study show an association between vitamin D deficiency and vitamin D insufficiency with nephropathy in a sample of US adults with diabetes. Furthermore, this association remains despite adjusting for race/ethnicity, the presence of hypertension, and medication use as well as other factors, demonstrating a robust relationship. This is one of the first studies in humans showing this association. Because of the cross-sectional na-

Table 3. Logistic Regression Predicting Nephropathy Among Adults ( $\geq 20$ Years 0ld) With Diabetes

\begin{tabular}{lccc}
\hline Vitamin D (ng/ML) & Odds Ratio (95\% CI) & Odds Ratio (95\% CI)* & Odds Ratio (95\% CI) $^{*}$ \\
\hline$<20$ & $1.96(1.21-3.19)$ & $1.78(1.04-3.06)$ & $1.85(1.06-3.23)$ \\
20 to 29 & $1.77(1.11-2.81)$ & $1.62(1.03-2.55)$ & $1.79(1.12-2.85)$ \\
$\geq 30$ & 1.00 & 1.00 & 1.00 \\
\hline
\end{tabular}

*Regression also controls for: age, gender, race/ethnicity.

${ }^{\dagger}$ Regression also controls for: age, gender, race/ethnicity, hypertension, high cholesterol, smoking status, use of angiotensinconverting enzyme inhibitor or angiotensin II type 1 receptor blockers, obesity. 
ture of this study, we were unable to determine whether this association is present because vitamin $\mathrm{D}$ deficiency increases the risk of nephropathy or because nephropathy increases the risk of vitamin $\mathrm{D}$ deficiency. Previous studies suggest that the relationship between these 2 variables is such that both of these interactions may be occurring simultaneously. This study evaluates 25-OH-D, the circulating metabolite produced in the liver that is later metabolized in the kidneys to $1,25(\mathrm{OH}) 2 \mathrm{D} 3$. Based on this well-established pathway, renal insufficiency could not be the reason for the low levels of 25-OH-D seen in study. This suggests that studies to further describe the role of vitamin D as a possible risk marker or risk factor in diabetic nephropathy are needed to evaluate the impact of maintaining an adequate level of vitamin $\mathrm{D}$ on the progression of diabetic nephropathy. Studies demonstrating a benefit to vitamin D supplementation for total mortality suggest that this may be a strategy to consider in future studies. ${ }^{21}$ Further studies should also evaluate the value of vitamin $\mathrm{D}$ as an independent predictor of the progression of nephropathy as compared with other possible predictors.

This study also described the high prevalence of vitamin $\mathrm{D}$ deficiency in patients with diabetes, regardless of their kidney function. This finding highlights the need to improve screening for vitamin $\mathrm{D}$ deficiency in patients with diabetes, especially minority populations, because vitamin $\mathrm{D}$ is known to have a role in decreasing the risk of many chronic illnesses, including cancer, cardiovascular disease, and infectious diseases. ${ }^{10}$ This is especially pertinent for individuals with diabetes, who are at a higher risk of developing these conditions than the general population and thus may receive a greater benefit from having higher vitamin D levels. ${ }^{22-24}$

There are limitations to this study that should be considered. As previously mentioned, the crosssectional nature of the data limited inference and only allowed for the identification of associations. We were only able to measure $25-\mathrm{OH}-\mathrm{D}$ in this study, which did not allow us to evaluate the role of the kidney in metabolizing this form of vitamin D to the biologically active metabolite $1,25(\mathrm{OH}) 2 \mathrm{D} 3$. This is an accepted approach to the evaluation of vitamin $\mathrm{D}$ status because only a small amount of $25-\mathrm{OH}-\mathrm{D}$ is metabolized in the kidney. ${ }^{4,5} \mathrm{We}$ were unable to identify the month of the year in which respondents participated in the examination be- cause of confidentiality issues in the NHANES. However, NHANES data are collected throughout the year and across the country so we would not expect a bias in racial data collection during specific seasons of the year. Finally, there was no consensus on the level of 25-OH-D that denotes insufficiency. Thus, analyses were also performed evaluating another commonly used threshold ( $\geq 32 \mathrm{ng}$ / $\mathrm{ml})$, and these yielded similar results. ${ }^{25}$

\section{Conclusion}

This study demonstrated an association between vitamin $\mathrm{D}$ deficiency and vitamin $\mathrm{D}$ insufficiency with nephropathy in individuals with diabetes even after controlling for factors such as race/ethnicity and the presence of hypertension and use of ACE inhibitors or ARBs. The high prevalence of vitamin $\mathrm{D}$ deficiency and vitamin $\mathrm{D}$ insufficiency in individuals with diabetes, especially in minorities, suggest that further study of this relationship may lead to new interventions to delay the progression of diabetic nephropathy.

\section{References}

1. Gross JL, Azevedo MJ, Silveiro SP, Canani LH, Caramori ML, Zelmanovits T. Diabetic nephropathy: diagnosis, prevention and treament. Diabetes Care 2005;28:176-88.

2. Resnick HE, Foster GL, Bardlsey J, Ratner RE. Achievement of American Diabetes Assocation Clinical Practice Recommendations among US adults with diabetes, 1999-2002: The National Health and Nutrition Examination Survey. Diabetes Care 2006; 29:531-7.

3. American Diabetes Association. Diabetes and nephropathy (kidney complications). Available at: http://www. diabetes.org/diabetes-statistics/kidney-disease.jsp. Accessed July 7, 2009.

4. Holick MF. Vitamin D deficiency. N Engl J Med 2007;357:266-81.

5. National Kidney Foundation. K/DOQI clinical practice guidelines for bone metabolism and disease in chronic kidney disease. Am J Kidney Dis 2003; 42(Suppl 3):S1-S201.

6. Klaus G. Renoprotection with vitamin D: specific for diabetic nephropathy? Kidney Int 2008;73:141-3.

7. Zhang Z, Sun L, Wang Y, et al. Renoprotective role of the vitamin $\mathrm{D}$ receptor in diabetic nephropathy. Kidney Int 2008;73:163-71.

8. Kuhlmann A, Haas CS, Gross ML, et al. 1,25Dihydroxyvitamin D3 decreases podocyte loss and podocyte hypertrophy in the subtotally nephrectomized rat. Am J Physiol Renal Physiol 2004;286: F526-33. 
9. Schwarz U, Amann K, Orth SR, Simonaviciene A, Wessels S, Ritz E. Effect of 1,25 (OH)2 vitamin D3 on glomerulosclerosis in subtotally nephrectomized rats. Kidney Int 1998;53:1696-705.

10. Holick MF. Vitamin D for health and in chronic kidney disease. Semin Dial 2005;18:266-75.

11. Harris SS. Vitamin D and African Americans. J Nutr 2006;136:1126-9.

12. Looker AC, Dawson-Hughes B, Calvo MS, Gunter EW, Sahyoun NR. Serum 25-hydroxyvitamin D status of adolescents and adults in two seasonal subpopulations from NHANES III. Bone 2002;30:771-7.

13. Centers for Disease Control and Prevention, National Center for Health Statistics. NHANES Analytic Guidelines. Available at: http://www.cdc.gov/ nchs/data/nhanes/nhanes_general_guidelines_june_ 04.pdf. 2004. Accessed February 3, 2009.

14. Molitch ME, DeFronzo FA, Franz MJ, et al. Nephropathy in diabetes. Diabetes Care 2004;27(Suppl 1):S79-83.

15. Centers for Disease Control and Prevention, National Center for Health Statistics. NHANES 19992000 Data Release. Prescription medication subsection (RXQ_RX) of dietary supplements and prescription medication section (DSQ) sample person questionnaire. Available at: www.cdc.gov/nchs/ data/nhanes/frequency/rxq_rxdoc.pdf. Accessed July 7, 2009.

16. Centers for Disease Control and Prevention, National Center for Health Statistics. NHANES 20012002 data documentation. April 2005 SP questionnaire. Prescription medication subsection (RXQ_RX_B) of dietary supplements and prescription medication section (DSQ). Available at: www. cdc.gov/nchs/data/nhanes/nhanes_01_02/rxq_rx_b_doc.pdf. Accessed July 7, 2009.

17. Varughese GI, Lip GY. Antihypertensive therapy in diabetes mellitus: insights from ALLHAT and the Blood Pressure-Lowering Treatment Trialists' Collaboration meta-analysis. J Hum Hypertens 2005;19: 851-3.

18. Turnbull F, Neal B, Algert C, et al. Effects of different blood pressure-lowering regimens on major cardiovascular events in individuals with and without diabetes mellitus: results of prospectively designed overviews of randomized trials. Arch Intern Med 2005;165:1410-9.

19. Sawicki PT, Didjurgeit U, Muhlhauser I, Bender R, Heinemann L, Berger M. Smoking is associated with progression of diabetic nephropathy. Diabetes Care 1994;17:126-31.

20. Hovind P, Rossing P, Tarnow L, Parving HH. Smoking and progression of diabetic nephropathy in type 1 diabetes. Diabetes Care 2003;26:911-6.

21. Autier P, Gandini S. Vitamin D supplementation and total mortality: a meta-analysis of randomized controlled trials. Arch Intern Med 2007;167:1730-7.

22. Inoue M, Iwasaki M, Otani T, Sasazuki S, Noda M, Tsugane S. Diabetes mellitus and the risk of cancer: results from a large-scale population-based cohort study in Japan. Arch Intern Med 2006;166:1871-7.

23. Grundy SM, Howard BS, Sidney ER Jr, Robert R, Rita Bonow RO. Prevention Conference VI: Diabetes and Cardiovascular Disease: executive summary: conference proceeding for healthcare professionals from a special writing group of the American Heart Association. Circulation 2002;105:2231-9.

24. Bertoni AG, Sayda S, Brancati FL. Diabetes and the risk of infection- related mortality in the US. Diabetes Care 2001;24:1044-9.

25. Hollis BW. Circulating 25-hydroxyvitamin D levels indicative of vitamin D sufficiency: implications for establishing a new effective dietary intake recommendation for vitamin D. J Nutr 2005;135:317-22. 